Check for updates

Cite this: RSC Adv., 2019, 9, 35559

\title{
The concentration and origins of carboxylic acid groups in oil paint $\uparrow$
}

\author{
Lambert Baij, (D)*ab Louise Chassouant, ${ }^{a}$ Joen J. Hermans, (D) ${ }^{\text {ab }}$ Katrien Keune ${ }^{\mathrm{ab}}$ \\ and Piet D. ledema ${ }^{\mathrm{a}}$
}

Although the concentration of carboxylic acid $(\mathrm{COOH})$ groups is crucial to understand oil paint chemistry, analytical challenges hindered $\mathrm{COOH}$ quantification in complex polymerised oil samples thus far. The concentration of $\mathrm{COOH}$ groups is important in understanding oil paint degradation because it drives the breakdown of reactive inorganic pigments to dissolve in the oil network and form metal carboxylates. The metal ions in such an ionomeric polymer network can exchange with saturated fatty acids to form crystalline metal soaps (metal complexes of saturated fatty acids), leading to serious problems in many paintings worldwide. We developed two methods based on ATR-FTIR spectroscopy to accurately estimate the $\mathrm{COOH}$ concentration in artificially aged oil paint models. Using tailored model systems composed of linseed oil, $\mathrm{ZnO}$ and inert filler pigments, these dried oil paints were found to contain one $\mathrm{COOH}$ group per triacylglycerol unit. Model systems based on a mixture of long chain alcohols showed that the calculated $\mathrm{COOH}$ concentration originates from side chain autoxidation at low relative humidity $(\mathrm{RH})$. The influence of increasing $\mathrm{RH}$ and $\mathrm{ZnO}$ concentration on $\mathrm{COOH}$ formation was studied and high relative humidity conditions were shown to promote the formation of $\mathrm{COOH}$ groups. No significant ester hydrolysis was found under the conditions studied. Our results show the potential of quantitative analysis of oil paint model systems for aiding careful (re)evaluation of conservation strategies.

Received 27th August 2019

Accepted 26th October 2019

DOI: 10.1039/c9ra06776k

rsc.li/rsc-advances commercial ionomers, ${ }^{7}$ contains clusters of metal carboxylates (COOM), often identified by a broad asymmetric $\nu_{\mathrm{a}} \mathrm{COO}^{-}$ infrared (IR) absorption band. ${ }^{3,6}$ These ionomeric metal carboxylate complexes were discovered to represent an intermediate stage in paint ageing that can ultimately lead to the appearance of crystalline metal soaps (metal complexes of long chain saturated fatty acids). ${ }^{5}$ Metal soaps play an important role in many types of oil paint degradation. ${ }^{1}$

The concentration of $\mathrm{COOH}$ groups in polymerised oil is expected to be a crucial factor affecting the extent of oil paint degradation. Being an integral part of the mature oil paint binding medium, $\mathrm{COOH}$ groups are most likely the driving force for the release of metal ions by inorganic pigments and the formation of (network-bound) COOM. ${ }^{3}$ Furthermore, $\mathrm{COOH}$ groups indirectly determine the extent of metal soap formation, because before metal soap crystallisation can occur, networkbound COOM need to exchange with free SFAs. ${ }^{5}$ Although many $^{8-16}$ have studied extractable acids, the concentration of $\mathrm{COOH}$ groups linked to the polymer network has, to the best of our knowledge, never been quantified.

From a chemical point of view, oil paint is a mixture of mainly inorganic pigments, a drying oil consisting of triacylglycerides (TAGs) and a variety of possible additives. Linseed oil (LO) is widely used in oil paintings because it possesses excellent drying properties. LO consists of a mixture of TAGs, mostly containing linolenic acid (C18:3), linoleic acid
${ }^{a}$ Van 't Hoff Institute for Molecular Sciences, University of Amsterdam, PO box 94720, 1090GD Amsterdam, The Netherlands. E-mail: C.L.M.Baij@uva.nl; Tel: +31 20525 7143

${ }^{b}$ Rijksmuseum Amsterdam, Conservation and Science, PO box 74888, 1070DN Amsterdam, the Netherlands

$\dagger$ Electronic supplementary information (ESI) available. See DOI: 10.1039/c9ra06776k 


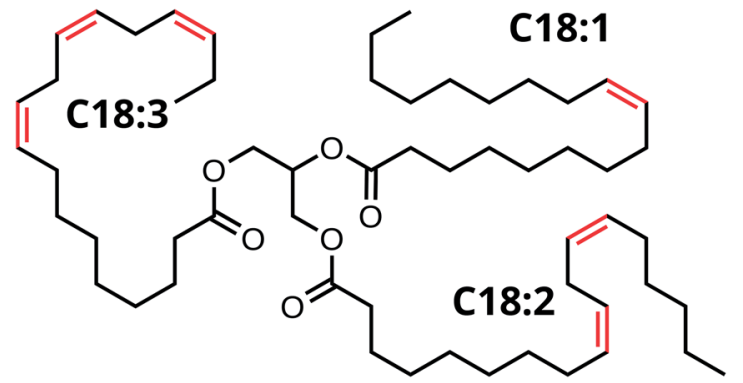

Fig. 1 Structure of a triacylglyceride (TAG) unit in linseed oil (LO), C18:3 denotes linolenic acid, C18:2 linoleic acid and C18:1 oleic acid

(C18:2), and oleic acid (C18:1) side chains (see Fig. 1). As the oil undergoes autoxidation reactions, ${ }^{17-19}$ the paint mixture becomes a complex heterogeneous polymer with solid pigment particles suspended in the densely cross-linked network. This polymer network contains mainly ether- or peroxy-type crosslinks formed through autoxidation of double bonds on fatty acid side chains. Over time, higher oxidation products of these oxygen cross-links result in the formation of aldehydes and $\mathrm{COOH}$ groups (see Scheme 1). It is important to note that $\mathrm{COOH}$ groups are a product of the autoxidation process (mechanism 2). Consequently, the ionomeric state is also found in relatively young oil paints. Upon ageing, hydrolysis of ester bonds can introduce additional $\mathrm{COOH}$ groups (mechanism 1). Since the two different mechanisms of $\mathrm{COOH}$ formation may dominate at different stages during the lifetime of an oil paint, we aim to distinguish them in our experiments.

The present paper focuses on the crucial role $\mathrm{COOH}$ groups play in pigment degradation. Quantifying the amount of $\mathrm{COOH}$ groups attached to a heterogeneous polymer network is a challenging task. Most spectroscopic, electrochemical or calorimetric methods to determine the acid concentration in vegetable oils require a homogeneous solution of the (nonpolymerised) oil in a solvent and only work for free fatty acids (FFAs). ${ }^{20,21}$ Because we are interested in the $\mathrm{COOH}$ groups linked to the polymer network, the conventional methods of breaking up TAGs using pyrolysis GC/MS do not give the desired information. ${ }^{22}$ Potentiometric titration of $\mathrm{COOH}$ groups ${ }^{23}$ proved to be time consuming and inaccurate since polymerised LO is extremely insoluble and the diffusion of water is very slow. ${ }^{24}$ Methods based on derivatization with fluoride transfer reagents ${ }^{25,26}$ showed the existence of acid groups but did not give a reproducible conversion when applied to our polymeric materials. Swollen-state ${ }^{13} \mathrm{C}$ NMR spectroscopy also enabled the detection of acid groups but was not used in a quantitative manner. ${ }^{27}$

Attenuated total reflection Fourier-transform infrared (ATRFTIR) spectroscopy is a powerful tool for the study of organic polymers and solid paint materials. However, ATR-FTIR does not allow for a direct observation of the $\mathrm{COOH}$ concentration in polymerised LO due to the overlapping IR absorption bands of the asymmetric carbonyl stretching vibration of the ester (COOR, $1738 \mathrm{~cm}^{-1}$ ), aldehyde ( $\mathrm{COH}, 1726 \mathrm{~cm}^{-1}$ ) and carboxylic acid (COOH, $1710 \mathrm{~cm}^{-1}$ ) groups (see Fig. S1†). Simple peak deconvolution is unreliable because additional overlapping absorption contributions from FFAs, ketones and $\nu(\mathrm{C}=\mathrm{C})$ bonds are present in this spectral region..$^{28} \mathrm{~A}$ practical solution is the complexation of $\mathrm{COOH}$ groups with $\mathrm{Zn}^{2+}$ ions (released by $\mathrm{ZnO}$ ), leading to the appearance of a broad, free-lying IR absorption band for zinc carboxylates (COOZn) centered around $1585 \mathrm{~cm}^{-1}$.,6 We have recently unequivocally assigned the structure and coordination in these COOZn complexes: they adopt either a coordination chain- or an oxo-type cluster structure. ${ }^{6}$ The COOZn IR absorption band can be used as a method to accurately estimate the concentration of $\mathrm{COOH}$ in polymerised LO that is accessible for reaction with zinc ions. This concentration is most relevant for oil paint degradation since amorphous $\mathrm{COOZn}$ is the intermediate in crystalline metal soap formation. Throughout this text, the COOZn band will be used as a measure for $\mathrm{COOH}$ concentration.

In our experiments, we monitor COOZn formation by varying the amounts of $\mathrm{ZnO}$ or $\mathrm{COOH}$ in a controlled manner. In one series of experiments, the $\mathrm{ZnO}$ concentration is increased at constant $\mathrm{COOH}$ concentration. In a second series of experiments, the acidity is varied under excess ZnO. Because acid groups in polymerised LO can form according to two mechanisms: (1) hydrolysis of ester bonds and (2) autoxidation of side chains double bonds (see Scheme 1), we also investigate which mechanism of $\mathrm{COOH}$ group formation dominates. Regular $\mathrm{LO}$ does not allow to discriminate between these two mechanisms of acid formation. We employ a mixture of alcohols obtained by reducing $\mathrm{LO}$ with $\mathrm{LiAlH}_{4}$, blocking the hydrolysis pathway and forming acid groups by autoxidation only. Because the concentration of acid groups in our model systems is not universally valid for aged paintings, we investigate how environmental conditions affect the $\mathrm{COOH}$ concentration. More specifically, the influence of $\mathrm{ZnO}$ on ester hydrolysis is investigated by examining samples at low and high relative humidity $(\mathrm{RH})$ as a function of $\mathrm{ZnO}$ concentration.

In this paper, we develop an analytical method to quantify the concentration of $\mathrm{COOH}$ groups attached to a complex polymerised oil network. Knowing the quantity and origins of $\mathrm{COOH}$ groups can lead to improved storage and conservation strategies and an extended lifetime of invaluable works of art.

\section{Materials and methods}

\section{Sample preparation}

Model paint samples containing ZnO (Sigma Aldrich, $\geq 99 \%$ ) and coated rutile $\mathrm{TiO}_{2}$ (Sigma Aldrich, $>99.9 \%$ ) or $\mathrm{ZnO}$ and $\mathrm{BaSO}_{4}$ (Kremer pigmente $58700, \geq 98 \%$ ) were made by grinding the pigments with cold-pressed untreated linseed oil (Kremer pigmente) in a $1: 1(\mathrm{w} / \mathrm{w})$ ratio to a smooth paste with mortar and pestle. SEM images of pigment particles are shown in Fig. S4. $\dagger$ The successful reduction of the esters in LO to alcohols was achieved using $\mathrm{LiAlH}_{4}$ in THF (see Fig. S7 and ESI $\dagger$ for details). Care was taken to keep the Pigment Volume Concentration (PVC) at $17-19 \%$ in all series. The mixture was applied to $50 \times 75 \mathrm{~mm}$ glass slides and spread with a draw-down bar to achieve a wet thickness of $190 \mu \mathrm{m}$. The samples were cured in the dark in air at $60{ }^{\circ} \mathrm{C}$ for 7 days at different $\mathrm{RH}$. $\mathrm{RH}$ was 
<smiles>[R]OC(=O)CCCCCC/C=C/C/C=C/CCCCC</smiles><smiles>[R20]C(=O)CCCCCCC=CC=CC(OOC)C(CCCC)C(C)(C)O</smiles>

mechanism 2: autoxidation

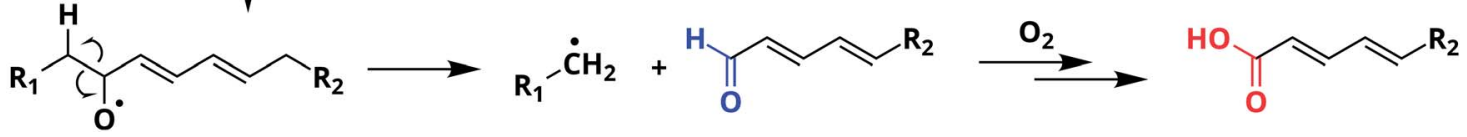

Scheme 1 Two mechanisms that lead to the formation of acid groups (in red) starting from the ester of linoleic acid: (1) hydrolysis and (2) autoxidation of side chain $\mathrm{C}=\mathrm{C}$ bonds. Note that autoxidation leads to additional products, including aldehydes (in blue).

controlled using a saturated $\mathrm{NaCl}$ solution (for $77 \% \mathrm{RH}$ ) in a closed container and was determined using a Rotronic HL-1D temperature and humidity data logger. For all measurements, 5 $\times 5 \mathrm{~mm}$ squares of the films were cut and lifted off the glass support for ATR-FTIR analysis. The exact sample composition is given in Tables S1-S6. $\dagger$

\section{ATR-FTIR spectroscopy}

ATR-FTIR spectra were measured on a PerkinElmer Frontier FTIR spectrometer fitted with a Pike GladiATR module equipped with a heated top plate and a diamond ATR-crystal $(\varnothing=3 \mathrm{~mm})$. Spectra were averaged over 4 scans. To integrate overlapping absorption bands, automated data correction and integration algorithms were written using Wolfram Mathematica software. For integration, IR spectra were averaged over either 3 or 5 measurements and the baseline was set to zero at $1820 \mathrm{~cm}^{-1}$. Spectra were normalised on the ester carbonyl $\left(1740 \mathrm{~cm}^{-1}\right)$ or $\mathrm{CH}_{2}\left(2920 \mathrm{~cm}^{-1}\right)$ band, after which the ester $\mathrm{CO}$ band was subtracted and integration performed between 1500$1650 \mathrm{~cm}^{-1}$. An estimated non-linear baseline correction was used to remove $\mathrm{TiO}_{2}$ absorption. An illustration of the background subtraction and band fitting procedures is given in Fig. S2 and S3. $\dagger$ In all graphs, error bars due to spectral variation are smaller than the symbols.

\section{X-ray diffraction}

X-ray diffraction (XRD) measurements on cured films were recorded with a Rigaku MiniFlex II desktop X-ray diffractometer using $\mathrm{Cu} \mathrm{K} \alpha$ radiation at $2.5^{\circ} \mathrm{min}^{-1}$ on $c a .10 \times 10 \mathrm{~mm}$ squares of paint film taped to a glass sample holder.

\section{Results and discussion}

\section{$\mathrm{COOH}$ concentration in $\mathrm{ZnO}$ paints}

Paints with increasing $\mathrm{ZnO}$ content. To explore the effect of $\mathrm{ZnO}$ concentration on $\mathrm{COOZn}$ formation, mixed pigment paint models containing various amounts of $\mathrm{ZnO}$ and $\mathrm{BaSO}_{4}$ filler were prepared (denoted $\mathrm{LO}-\mathrm{ZnO}-\mathrm{BaSO}_{4}$ ). The $\mathrm{BaSO}_{4}$ pigment is a well-known inert filler ${ }^{29}$ for white paints with a comparable density to $\mathrm{ZnO}$ ( $\mathrm{ZnO}$ and $\mathrm{BaSO}_{4}: 5.6$ and $4.5 \mathrm{~g} \mathrm{~cm}^{-3}$, respectively). Within the series, the total PVC was kept constant. The exact sample composition is given in Table S1. $\dagger$

Ester normalised FTIR spectra for samples containing 0.5$20 \mathrm{wt} \%$ of $\mathrm{ZnO}$ are depicted in Fig. 2a, showing an increasing concentration of COOZn with increasing $\mathrm{ZnO}$ content. Integrated absorption values for the $\nu_{\mathrm{a}} \mathrm{COOZn}$ IR absorption band at $1585 \mathrm{~cm}^{-1}$ are plotted as a function of $\mathrm{ZnO}$ concentration in Fig. 2b. Two regimes are visible in Fig. 2b, separated by a clear 'tipping point': a steep increase in COOZn up to $0.44 \mathrm{~mol} \mathrm{~L}^{-1}$ $\mathrm{ZnO}$ in $\mathrm{LO}(\approx 4.5 \mathrm{wt} \%$ of $\mathrm{ZnO})$ and a minimal increase in COOZn at concentration above $0.44 \mathrm{~mol} \mathrm{~L}^{-1}$. These results indicate that below $0.44 \mathrm{~mol} \mathrm{~L}^{-1} \mathrm{ZnO}$, part of the acid groups are complexated with zinc ions but there is insufficient $\mathrm{ZnO}$ present to neutralise all acid groups. The complete conversion of ZnO below $0.44 \mathrm{~mol} \mathrm{~L}^{-1}$ was confirmed by XRD (see Fig. S5†). Above $0.44 \mathrm{~mol} \mathrm{~L}^{-1}$, an excess $\mathrm{ZnO}$ is present and all accessible acid groups are complexated with zinc. Consequently, the tipping point can be used to calculate the concentration of $\mathrm{COOH}$ group available for reaction with $\mathrm{ZnO}$ : at this point the concentration of $\mathrm{COOH}$ is equivalent to twice the concentration of COOZn (and thus $\mathrm{ZnO}$ ). This approach leads to a calculated [COOH] of $0.88 \mathrm{~mol} \mathrm{~L}^{-1}$ and a molar [COOH]/[COOR] ratio of 0.35 . This result means that for roughly every three COOR functionalities, one $\mathrm{COOH}$ group is formed. In absence of ester hydrolysis, this corresponds to about one $\mathrm{COOH}$ group per triacylglycerol (TAG) unit or LO molecule.

Standard addition of sorbic acid. To test if additional acid groups in the linseed oil binder would result in the formation of additional COOZn, paints with increasing acidity were synthesised by cross-linking sorbic acid (SA, 2,4-hexadienoate) into $\mathrm{ZnO}$ based paint model systems (LO-ZnO-SA). Using the standard addition method, these experiments form a second method of $\mathrm{COOH}$ quantification. A constant PVC with a $\mathrm{ZnO}$ to LO ratio of $1: 1(\mathrm{w} / \mathrm{w})$ was used in this experiment, ensuring an large excess of ZnO. The effect of functionalizing LO with additional acid groups on the COOZn IR absorption band at $1585 \mathrm{~cm}^{-1}$ is shown in Fig. 3a. Integrated absorption values of 

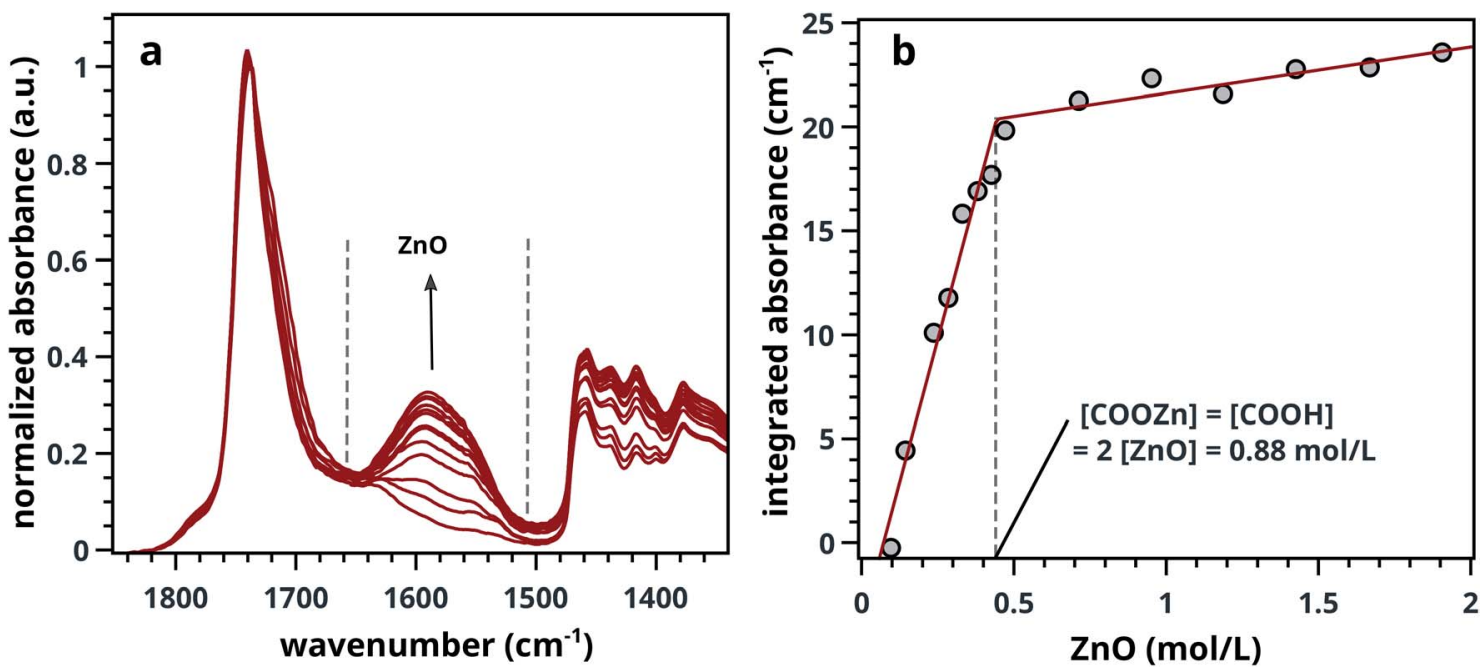

Fig. 2 (a) Normalised ATR-FTIR spectra for $\mathrm{LO}-\mathrm{ZnO}-\mathrm{BaSO}_{4}$ from $0.14-1.8 \mathrm{~mol} \mathrm{~L}^{-1}$ of added SA (0.0-20 wt\%). Dashed lines indicate band integration limits. (b) Integrated absorption values of COOZn band, clearly showing the 'tipping point' (dashed line) at 0.44 mol $\mathrm{L}^{-1} \mathrm{ZnO}$ marking complete $\mathrm{COOH}$ neutralisation. Further increase of $\mathrm{ZnO}$ does not increase the amount of $\mathrm{COOZn}$. See Fig. S2 $\uparrow$ for details on spectral processing.

the COOZn band are plotted as a function of added SA in Fig. 3b. Evidently, there is a linear $\left(R^{2}=0.97\right)$ relationship between the concentration of acid groups and the COOZn band, confirming the tendency of these systems to form COOZn as long as a source of zinc $(\mathrm{ZnO})$ is present. The concentration of acid groups in pure $\mathrm{ZnO}-\mathrm{LO}$ (without $\mathrm{SA}$ ) was calculated to be $0.86 \mathrm{~mol} \mathrm{~L}^{-1}$, resulting in a $[\mathrm{COOH}] /[\mathrm{COOR}]$ ratio of 0.32 (Fig. 3b). This result is in excellent agreement with our previous result obtained with mixed $\mathrm{ZnO} / \mathrm{BaSO}_{4}$ paints.

\section{The origin of $\mathrm{COOH}$ formation}

Having established a method to determine the $\mathrm{COOH}$ concentration in our paint samples, we proceed to investigate whether these acid groups originate from autoxidation of side chain double bonds or from the hydrolysis of ester carbonyl functionalities. Effects of increasing $\mathrm{RH}$ and $\mathrm{ZnO}$ concentration on COOZn formation are investigated.

Autoxidation. The relative amount of autoxidation and the effect of $\mathrm{ZnO}$ concentration on COOZn formation was studied. A mixture of alcohols obtained by reducing the esters in linseed oil to alcohols (reduced LO, rLO) was used as a binding medium instead of LO. This approach ensures that all COOZn formation results from autoxidation. Model paint samples containing rLO with varying amounts of $\mathrm{ZnO}$ and $\mathrm{TiO}_{2}$ fillers $\left(\mathrm{rLO}-\mathrm{ZnO}-\mathrm{TiO}_{2}\right.$ ) were made. Coated rutile $\mathrm{TiO}_{2}$ fillers were selected for the highly inert properties and low photocatalytic activity. ${ }^{30}$ In order to compare the two mechanisms of $\mathrm{COOH}$ formation (Scheme 1), reduced LO containing model paints were compared with samples made with ordinary LO.

Comparing rLO-ZnO- $\mathrm{TiO}_{2}$ (triangles) with $\mathrm{LO}-\mathrm{ZnO}-\mathrm{TiO}_{2}$ (squares) in Fig. 4, it is clear that using rLO does not
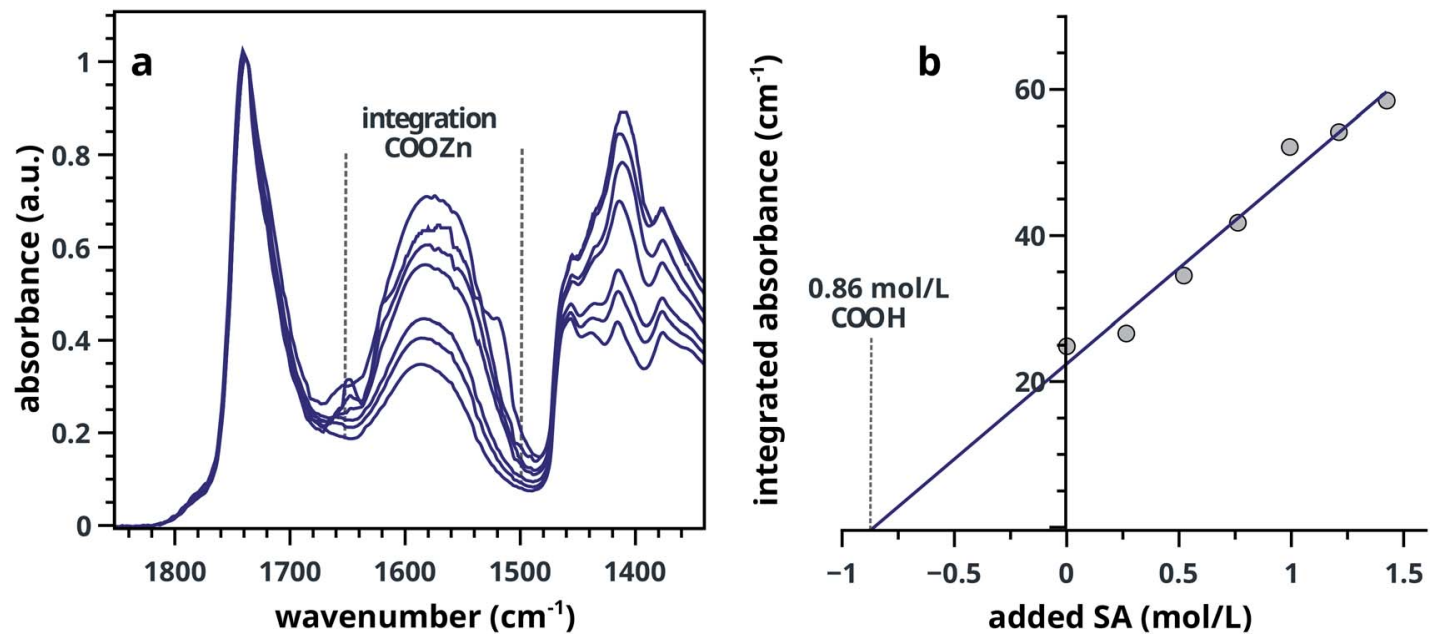

Fig. 3 (a) Selection of FTIR spectra of LO-ZnO-SA with added SA from 0.0-1.5 mol L ${ }^{-1}$ of $\mathrm{ZnO}$ in $\mathrm{LO}$ (0-60 wt\%). Dashed lines in indicate band integration limits. (b) Integrated absorption values of COOZn band showing the linear relationship between added SA and COOZn absorption. 


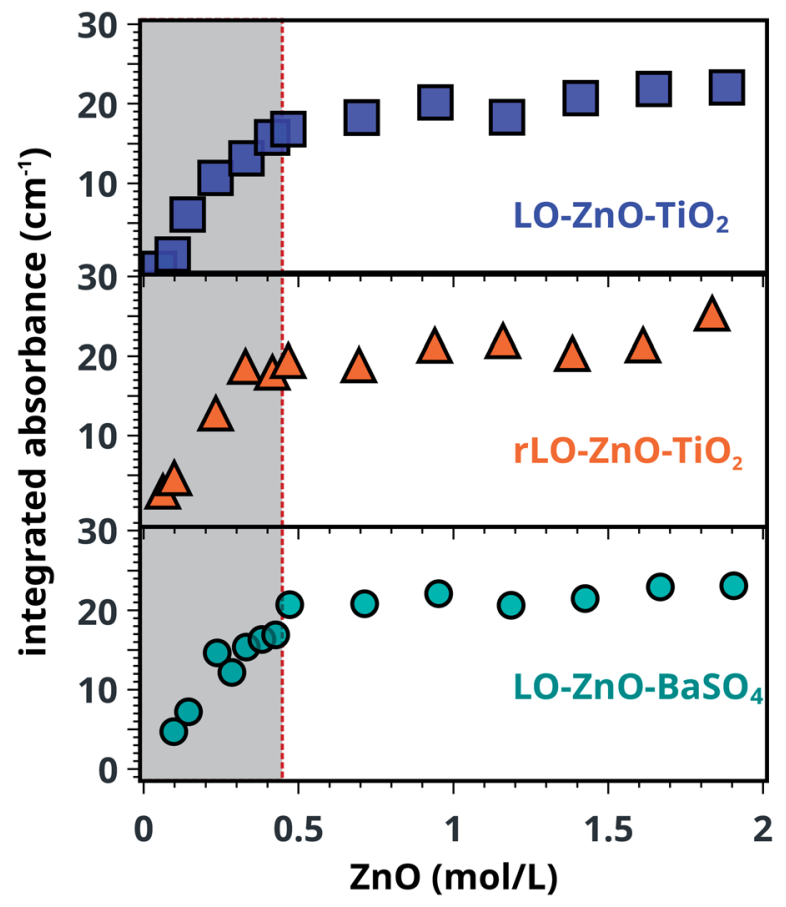

Fig. 4 Integrated absorbance of the COOZn band for $\mathrm{LO}-\mathrm{ZnO}-\mathrm{TiO}_{2}$ $\mathrm{rLO}-\mathrm{ZnO}-\mathrm{TiO}_{2}$ and $\mathrm{LO}-\mathrm{ZnO}-\mathrm{BaSO}_{4}$ model systems. The dotted line indicates the previously found tipping point at $0.44 \mathrm{~mol} \mathrm{~L}^{-1} \mathrm{ZnO}$. All IR spectra were normalised on the $\mathrm{CH}_{2}$ vibration $\left(2929 \mathrm{~cm}^{-1}\right.$ ) before integration.

significantly affect $\mathrm{COOZn}$ formation at low $\mathrm{ZnO}$ concentrations (0.1-2 $\left.\mathrm{mol} \mathrm{L}^{-1}\right)$. Hence, we conclude that the previously calculated $\mathrm{COOH}$ concentration of $0.88 \mathrm{~mol} \mathrm{~L}^{-1}$ is the result of side chain autoxidation (Scheme 1, pathway 2). Fig. 4 also shows that the integrated absorption values of the COOZn band in LO$\mathrm{ZnO}_{-} \mathrm{BaSO}_{4}$ (circles) and $\mathrm{LO}-\mathrm{ZnO}-\mathrm{TiO}_{2}$ (squares) are highly similar, verifying the chemical inertness of the chosen $\mathrm{TiO}_{2}$ and $\mathrm{BaSO}_{4}$ fillers. To confirm that autoxidation is the main pathway leading to the formation of $\mathrm{COOH}$ groups in $\mathrm{rLO}-\mathrm{ZnO}-\mathrm{TiO}_{2}$ samples, we cured a mixture of fully saturated triglycerides (tristearin) and $\mathrm{ZnO}\left(1: 1\right.$ by wt.) for one week at $60{ }^{\circ} \mathrm{C}$ and $12 \%$ $\mathrm{RH}$. In this mixture, no COOZn was formed after one week (see Fig. S9†).

Hydrolysis. Having established that autoxidation is dominant at low $\mathrm{RH}$, we investigated high $\mathrm{RH}$ conditions and increasing $\mathrm{ZnO}$ concentrations because these factors likely promote ester hydrolysis. A number of recent publications have already demonstrated the relationship between the presence of $\mathrm{ZnO}^{15}$ or high $\mathrm{RH}$ conditions and the formation of organic acids in paint extracts. ${ }^{\mathbf{1 4}, 16}$ We compared $\mathrm{LO}-\mathrm{ZnO}-\mathrm{TiO}_{2}$ and rLO$\mathrm{ZnO}-\mathrm{TiO}_{2}$ paint models cured in dry $(12 \% \mathrm{RH})$ and wet conditions $(77 \% \mathrm{RH})$. A large $\mathrm{ZnO}$ concentration range of 3-9 $\mathrm{mol} \mathrm{L}^{-1}$ (30-90 wt\% of $\mathrm{ZnO}$ in LO) was studied.

Integrated absorbance values of the $\mathrm{COOZn}$ band at $1585 \mathrm{~cm}^{-1}$ for $\mathrm{LO}-\mathrm{ZnO}-\mathrm{TiO}_{2}$ and $\mathrm{rLO}-\mathrm{ZnO}-\mathrm{TiO}_{2}$ cured in dry and wet conditions are plotted as a function of $\mathrm{ZnO}$ concentration in Fig. 5. The integrated COOZn absorbance for both systems cured in $77 \% \mathrm{RH}$ conditions is significantly higher than

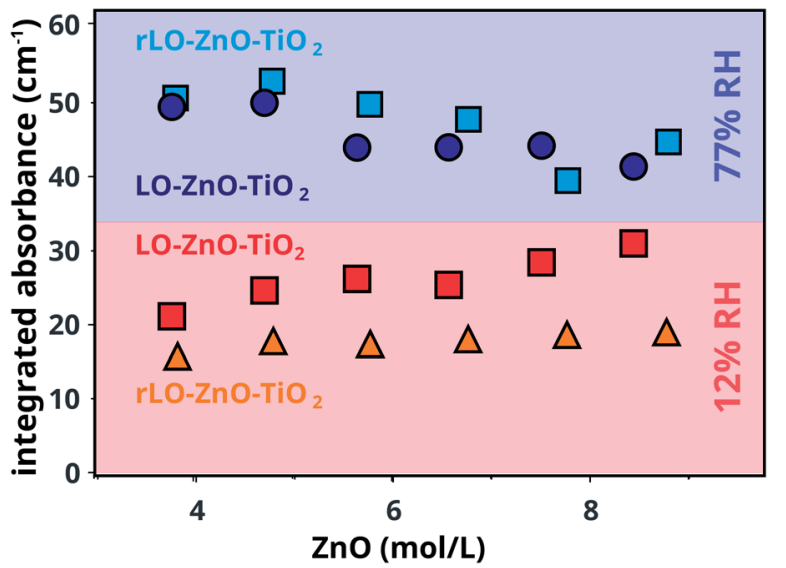

Fig. 5 Integrated absorbance of the COOZn band for $\mathrm{LO}-\mathrm{ZnO}-\mathrm{TiO}_{2}$ and $\mathrm{rLO}-\mathrm{ZnO}-\mathrm{TiO}_{2}$ from $30-90$ wt $\%$ cured in $12 \%$ and $77 \% \mathrm{RH}$ at $60{ }^{\circ} \mathrm{C}$ for 7 days. All IR spectra were normalised on the $\mathrm{CH}_{2}$ vibration $\left(2929 \mathrm{~cm}^{-1}\right)$ before integration.

when cured at $12 \% \mathrm{RH}$ (Fig. 5). Interestingly, both $\mathrm{LO}-\mathrm{ZnO}-$ $\mathrm{TiO}_{2}$ and $\mathrm{rLO}-\mathrm{ZnO}-\mathrm{TiO}_{2}$ show this effect, indicating that autoxidation is also the dominant pathway for $\mathrm{COOH}$ formation at high $\mathrm{RH}$ conditions and high $\mathrm{ZnO}$ concentrations. Previous research has shown that the oxygen uptake and peroxide decomposition rate in methyl linoleate are, in the first 80 hours, lower at higher water activities, resulting in a lower quantity of carbonyl compounds. ${ }^{31}$ Upon longer autoxidation times of up to two weeks, the production rates of hydroperoxides and conjugated dienoic acids were found to increase with increasing water activities. ${ }^{32}$ Water can thus stabilise and destabilise intermediates during different stages of the autoxidation pathway, resulting in an increased formation of $\mathrm{COOH}$ groups for long oxidation times. This can explain the increased COOZn formation at $77 \% \mathrm{RH}$ conditions in our measurements.

Comparing both systems at $12 \% \mathrm{RH}$, a small but significant difference is visible: the integrated absorbance for the COOZn band is consistently larger for $\mathrm{LO}-\mathrm{ZnO}-\mathrm{TiO}_{2}$ and seems to increase with increasing $\mathrm{ZnO}$ concentration. It is known that the low concentrations of free FAs $(0.5 \mathrm{wt} \%)$ can significantly increase the rate of autoxidation in methyl linoleate. ${ }^{33}$ The presence of free FAs in the regular LO may thus explain the formation of more $\mathrm{COOZn}$ in $\mathrm{LO}-\mathrm{ZnO}-\mathrm{TiO}_{2}$. This effect is not visible at $77 \% \mathrm{RH}$, suggesting that the effects of water on autoxidation are stronger than the effects of free FAs at high humidity. We currently do not have a satisfying explanation for the increase in COOZn with increasing $\mathrm{ZnO}$ at $12 \% \mathrm{RH}$ for $\mathrm{LO}-$ $\mathrm{ZnO}-\mathrm{TiO}_{2}$. Since we have shown that there is no hydrolysis of ester bonds in a mixture of $\mathrm{ZnO}$ and tristearin at $12 \% \mathrm{RH}$, hydrolysis can not explain this effect.

\section{Conclusions}

The concentration of acid groups in analytically challenging polymerised oil paint models was quantified using ATR-FTIR. Because the formation of $\mathrm{COOH}$ groups drives the release of zinc ions from $\mathrm{ZnO}$ pigment to form $\mathrm{COOZn}$, this mechanism 
can be used to determine the concentration of $\mathrm{COOH}$ groups available for coordination with zinc ions. The $\mathrm{COOH}$ concentration in $\mathrm{ZnO}$ paint models was calculated to be roughly one $\mathrm{COOH}$ group per TAG unit. This result was confirmed using the standard addition of sorbic acid to linseed oil in excess of $\mathrm{ZnO}$.

At low $\mathrm{ZnO}$ concentrations low $\mathrm{RH}, \mathrm{COOH}$ groups were found to form by autoxidation only. To investigate conditions that likely promote ester hydrolysis, the effects of moisture on $\mathrm{COOH}$ formation were studied over a wide range of $\mathrm{ZnO}$ concentrations. A strong increase in COOZn was observed at $77 \% \mathrm{RH}$ compared to $12 \% \mathrm{RH}$ due to an accelerating effect of water on $\mathrm{COOH}$ formation. No hydrolysis was observed under the conditions studied, indicating that oil paints are, in the initial stage of curing, quite resistant to hydrolysis.

Our results demonstrate that smart design of models systems enable a better understanding of oil paint degradation, aiding the improvement of storage and conservation strategies.

\section{Conflicts of interest}

There are no conflicts of interest to declare.

\section{Acknowledgements}

This research is funded by the EU Horizon 2020 research and innovation program under agreement No. 646063 and the Bennink Foundation/Rijksmuseum Fonds.

\section{References}

1 F. Casadio, K. Keune, P. Noble, A. van Loon, E. Hendriks, S. Centeno and G. Osmond, Metal Soaps in Art: Conservation and Research, Springer International Publishing, 2019.

2 J. J. Hermans, K. Keune, A. van Loon and P. D. Iedema, J. Anal. At. Spectrom., 2015, 30, 1600-1608.

3 J. J. Hermans, K. Keune, A. van Loon, R. W. Corkery and P. D. Iedema, RSC Adv., 2016, 6, 93363-93369.

4 F. Gabrieli, F. Rosi, A. Vichi, L. Cartechini, L. Pensabene Buemi, S. G. Kazarian and C. Miliani, Anal. Chem., 2017, 89, 1283-1289.

5 L. Baij, J. J. Hermans, K. Keune and P. Iedema, Angew. Chem., Int. Ed., 2018, 57, 7351-7354.

6 J. J. Hermans, L. Baij, M. Koenis, K. Keune, P. D. Iedema and S. Woutersen, Sci. Adv., 2019, 5, eaaw3592.

7 B. A. Brozoski, P. C. Painter and M. M. Coleman, Macromolecules, 1984, 17, 1591-1594.

8 P. L. Jones, Stud. Conserv., 1965, 10, 119.

9 J. D. van den Berg, K. J. van den Berg and J. J. Boon, J. Chromatogr. A, 2002, 950(1), 195-211.
10 K. Sutherland, Stud. Conserv., 2003, 48, 111-135.

11 A. Spyros and D. Anglos, Anal. Chem., 2004, 76, 4929-4936.

12 I. Bonaduce, L. Carlyle, M. P. Colombini, C. Duce, C. Ferrari, E. Ribechini, P. Selleri and M. R. Tiné, PLoS One, 2012, 7, e49333.

13 D. Banti, J. La Nasa, A. L. Tenorio, F. Modugno, K. J. van den Berg, J. Lee, B. Ormsby, A. Burnstock and I. Bonaduce, RSC Adv., 2018, 8, 6001-6012.

14 J. La Nasa, F. Modugno, M. Aloisi, A. Lluveras-Tenorio and I. Bonaduce, Anal. Chim. Acta, 2018, 1001, 51-58.

15 J. Lee, I. Bonaduce, F. Modugno, J. La Nasa, B. Ormsby and K. J. van den Berg, Microchem. J., 2018, 138, 282-295.

16 F. Modugno, F. D. Gianvincenzo, I. Degano, I. Dorothé van der Werf, I. Bonaduce, K. J. van den Berg, F. Di Gianvincenzo, I. Degano, I. D. van der Werf, I. Bonaduce and K. J. van den Berg, Sci. Rep., 2019, 9, 5533.

17 M. Lazzari and O. Chiantore, Polym. Degrad. Stab., 1999, 65, 303-313.

18 R. van Gorkum and E. Bouwman, Coord. Chem. Rev., 2005, 249, 1709-1728.

19 M. D. Soucek, T. Khattab and J. Wu, Prog. Org. Coat., 2012, 73, 435-454.

20 X. Jiang, S. Li, G. Xiang, Q. Li, L. Fan, L. He and K. Gu, Food Chem., 2016, 212, 585-589.

21 S. A. Mahesar, S. T. H. Sherazi, A. R. Khaskheli, A. A. Kandhro and S. Uddin, Anal. Methods, 2014, 6, 4956-4963.

22 M. R. Schilling, A. Heginbotham, H. van Keulen and M. Szelewski, Stud. Conserv., 2016, 61, 3-27.

23 H. Suzuki, B. Wang, R. Yoshida and E. Kokufuta, Langmuir, 1999, 15, 4283-4288.

24 L. Baij, J. J. Hermans, K. Keune and P. D. Iedema, Macromolecules, 2018, 51, 7134-7144.

25 J. Mallégol, J.-L. Gardette and J. Lemaire, J. Am. Oil Chem. Soc., 1999, 76, 967-976.

26 J. Mallégol, J. Lemaire and J. L. Gardette, Prog. Org. Coat., 2000, 39, 107-113.

27 G. Marshall, M. Cudby, K. Smith, T. Stevenson, K. Packer and R. Harris, Polymer, 1987, 28, 1093-1097.

28 L. de Viguerie, P. Payard, E. Portero, P. Walter and M. Cotte, Prog. Org. Coat., 2016, 93, 46-60.

29 Artists Pigments, ed. R. Feller, Cambridge University Press, Cambridge, 1986, vol. 1, p. 61.

30 B. van Driel, P. Kooyman, K. van den Berg, A. Schmidt-Ott and J. Dik, Microchem. J., 2016, 126, 162-171.

31 A. G. Gopala Krishna and J. V. Prabhakar, J. Am. Oil Chem. Soc., 1992, 69, 178-183.

32 E. Choe and S. Oh, J. Food Sci., 2013, 78, C1144-C1151.

33 K. Miyashita and T. Takagi, J. Am. Oil Chem. Soc., 1986, 63, 1380-1384. 